\title{
ENSINO (D)E LITERATURA: (DES)ENCONTROS NA FORMAÇÃO DO PROFESSOR DE INGLÊS
}

\author{
TEACHING OF/AND LITERATURE: \\ ASSONANCES/DISSONANCES IN ENGLISH TEACHER EDUCATION
}

\author{
Cristiane Carvalho de Paula Brito* \\ Ivan Marcos Ribeiro**
}

\begin{abstract}
RESUMO
Neste artigo, visamos refletir sobre o uso da literatura em aulas de língua inglesa (LI) voltadas para a formação do professor. Mais especificamente, interessa-nos responder a dois principais questionamentos, a saber: como ensejar práticas de leitura na universidade que possibilitem ao licenciando trabalhar o texto como materialidade linguístico-discursiva, por meio da qual ele possa se constituir leitor e (futuro) professor? E de que forma o trabalho com o texto literário pode contribuir para tal processo? Para isso, partimos da desconstrução das dicotomias entre lingua/literatura e aprender língua/aprender a ser professor de língua. Nossa discussão se delimita a algumas considerações sobre o currículo de um curso de Letras/Inglês, em uma universidade pública mineira, e sobre uma experiência com textos literários, em uma disciplina voltada para o desenvolvimento da leitura em LI, na referida instituição. Nossas análises apontam que, apesar de mudanças, o foco do currículo ainda recai sobretudo na periodização literária, havendo pouco espaço para a relação com o ensino. As propostas de abordagem do texto literário, por sua vez, acenam para possibilidades de se trabalhar uma estética-ética discursiva que possa incidir na constituição do futuro professor ao promover experiências de tomada responsivo-responsável da palavra em uma língua outra.

Palavras-chave: literatura; ensino-aprendizagem de língua inglesa; formação docente.
\end{abstract}

\section{ABSTRACT}

In this paper we aim to reflect upon the use of literature in English classes focused on teacher education. More specifically, we are interested in answering two main questions, namely: how to provide reading practices in the university which will make it possible for the future teacher to work with the text as a linguistic-discursive materiality, by means of which they will become both a reader and a (future) teacher? And in which ways can the work with the literary text contribute to such a process? In order to do so, we start from the deconstruction of the dichotomies between language/literature and between learn a language/learn to teach a language. Our discussion is limited to some considerations about the curriculum of an English Language Teacher Education Program, in a public university in Minas Gerais State, and also on an experience with literary texts, in a subject aimed at the development of reading in English. Our analyses point out to the fact that, despite changes, the literature curricular proposal still focuses on periodization narrowing the relationship with teaching. The pedagogical proposals of the literary text, in turn, point to possibilities of working a discursive aesthetics-ethics which may affect the constitution of the future teacher by promoting experiences of responsive-responsible meaning making in another language.

Keywords: literature; English teaching-learning; teacher education.

Dado que a experiência é uma relação, o importante não é o texto, senão a relação com o texto (LARROSA, 2011, p. 9)

O importante (...) é que a leitura (...) pode ajudar-me a formar ou a transformar minha própria linguagem, a falar por mim mesmo, ou a escrever por mim mesmo, em primeira pessoa, com minhas próprias palavras.

(LARROSA, 2011, p. 10-11)

\section{(DES)ENCONTROS INICIAIS}

A discussão sobre o trabalho com a literatura no ensino de línguas estrangeiras (LE), apesar de não muito abundante, não é nova. Türker, por exemplo, em 1991, no texto intitulado Using "literature" in language teaching, argumenta que o uso de textos literários no ensino: contribui para o desenvolvimento de todas as habilidades (não só a da leitura); nos permite compreender experiências e eventos da vida real, a partir de sua análise; aperfeiçoa os leitores cultural e educacionalmente; e contribui para a aquisição de habilidades de análise e crítica. Sobre uma dificuldade nessa relação/conflito de áreas, Türker ainda afirma que

\footnotetext{
* Universidade Federal de Uberlândia (UFU), Uberlândia, MG, Brasil. cristiane.brito@ufu.br Orcid: https://orcid.org/0000-0002-7210-6635

** Universidade Federal de Uberlândia (UFU), Uberlândia, MG, Brasil. imribeiro@ufu.br Orcid: https://orcid.org/0000-0002-1800-5489
} 
Ensinar literatura de língua estrangeira para estudantes universitários não-nativos nem sempre é uma tarefa fácil. Em alguns casos, é uma situação extraída do absurdo, na qual os alunos são obrigados a ler livros em uma língua que mal entendem e então discutir estrutura, estilo do autor, etc. Sob tais circunstâncias, parece ser um contrassenso crer que os estudantes estejam aprendendo algo de significativo. TÜRKER, 1991, p. 301')

Não sem razão, a abordagem de um texto literário pode ser na realidade dificultadora de compreensão, na maioria dos casos, e mesmo em cursos com alunos proficientes, a literatura também pode causar conflitos na aprendizagem da LE, desmotivando os aprendizes².

Ur (1996), na obra A course in language teaching, relaciona o uso de gêneros literários aos elementos culturais relativos à língua-alvo, e sua relevância em sala de aula ao discutir o uso dos conteúdos não-linguísticos. De maneira geral, a autora lança questionamentos ao leitor quanto à utilidade/finalidade do uso da literatura em tal contexto, para depois realizar o que comumente se discute quanto a esse uso: vantagens e desvantagens do ensino de língua pela literatura. Entretanto, e felizmente, Ur se desloca para alguns poucos, mas bons exemplos de como lidar com o conteúdo literário nas aulas de língua, tecendo esquemas estruturados em três bases: Encounter and impact (primeiras impressões); Understanding and familiarization (contato aprofundado); Analysis and interpretation (consolidação do entendimento). Ou seja, da apresentação do texto até a discussão com os alunos, há etapas que a autora considera oportunas para uma eficácia no uso do conteúdo literário para se aprender o idioma. Ao mencionar a opinião de alguns professores que trazem a literatura para o ensino de língua, Ur faz a seguinte assertiva quanto à intervenção do professor nas discussões do corpus literário:

O que ocorre caso os aprendizes construam uma interpretação que, parecendo clara para você, esteja totalmente dissonante da intenção do autor? Se você tem familiaridade com a obra literária em questão, pode achar muito difícil, senão impossível, isentar os alunos dessas concepções 'equivocadas'; será mais fácil se estiver menos envolvido com a literatura, ou se estiver mais comprometido a permitir interpretações livres do aluno que resultem em enriquecimento pessoal e aprendizagem mais profícua. (UR, 1996, p. 205. Tradução nossa) $)^{3}$

Quanto a essa assertiva, julgamos que hoje tal intervenção deveria ser considerada apenas para mediar o debate do texto em princípio, e a partir do entendimento do conteúdo, elevar a discussão para um nível mais confiante do uso do idioma, bem como tecer questões relativas àquilo que o texto traz em termos de expressão individual. Ademais, a chamada "intenção do autor" não mais é considerada em muitos níveis, e as concepções "erradas", sejam quais forem, poderão encontrar esteio em uma ou outra interpretação, tendo em vista a prática do idioma, e também o entendimento de cada aprendiz.

Assim, Ur termina as suas considerações quanto ao uso da literatura trazendo exemplos de dois textos literários para o uso em sala de aula de língua e afirmando que as aulas de conteúdo literário, por extensão, podem terminar com uma releitura do texto em foco. Por fim, traz uma lista de referências adicionais para leitura, dentre as quais cita a autora Gillian Lazar.

Lazar (1993), por sua vez, publica uma obra mais consistente e mais pluralizada quanto ao assunto, como se percebe pelo título: Literature and Language Teaching. Essa obra é estruturada por temas e por estratégias, que vão desde a clássica discussão sobre as vantagens e desvantagens do uso de literatura nas aulas de línguas até a importância de se existirem os chamados Literature self-access centers, nos quais se disponibiliza uma gama de textos literários para livre escolha dos leitores. Lazar também discute a importância de se conciliar a escrita criativa com o auxílio de ambas as disciplinas, e indica as peculiaridades do trabalho com cada gênero. Nesse sentido, podemos afirmar que a discussão do tema se torna abrangente e se torna, obviamente, um dos pilares para uma (re)visão do entrelaçamento entre

1. Nossa tradução do original: "Teaching Foreign Language Literature to non-native-speaking university students is not always an easy task. In some cases, it is itself a situation taken from the absurd, in which the students are supposed to read books in a language they hardly understand and then they discuss structure, the author's style etc. Under such circumstances, it may be absurd to believe that the students are learning anything of significance". (TURKER, 1991, p. 301)

2. É preciso mencionar que a presença da literatura em aulas de LE data do século XIX. O Método da Gramática-Tradução, em voga na Europa entre 1840 e 1940 (RICHARDS; RODGERS, 1986), se pautava na tradução e versão de textos literários, sendo que praticamente nenhuma ênfase era dada ao desenvolvimento da oralidade, haja vista que a razão para se aprender a língua alvo residia na possibilidade de ler sua literatura.

3. Nossa tradução do original: "What happens if the learners construct an interpretation that, it seems clear to you, is in total disagreement with the author's intention? If you are particularly attached to the piece of literature in question, you may find it extremely difficult, if not impossible, to allow learners to get away with such 'wrong' conceptions; you will find it easier if you are less involved with the literature, or if you are more committed to allowing free learner interpretations on the grounds that this results in ultimate personal enrichment and more valuable learning". (UR, 1996, p. 205) 
literatura e língua, uma vez que, como apontado acima, o foco nessas duas disciplinas era basicamente leitura, e Lazar propõe explorar as habilidades linguísticas embasadas no/pelo texto literário.

Como estudos mais atuais, em termos cronológicos, podemos citar a obra de Naji; Subramaniam; White (2019). Os autores abordam a importância da literatura na aprendizagem de línguas; discutem sua relevância no desenvolvimento de competências necessárias à vida contemporânea; oferecem inúmeros exemplos de atividades pedagógicas; discutem a questão da literatura digital em suas diferentes facetas; apresentam diferentes modos de engajamento com o texto literário; exploram a relação entre cultura e literatura e suas implicações para o ensino de línguas, dentre outros.

É interessante pensar em como esses autores, amparados também por teorias precedentes, focam, dentre muitos aspectos, na perspectiva de a qual literatura o aprendiz deve ser exposto ou qual delas o docente deve adotar em seu currículo. Nesse sentido é imperativo pensar que cada texto deve adequar-se aos níveis de proficiência do aluno, seja iniciante, seja avançado. A provável resposta à questão sobre a qual literatura o aprendiz deve ser exposto seria aquela em que houvesse afinidade cultural, acesso mais fluido ao vocabulário, possibilidade de uso dos conceitos depreendidos da obra literária em questão e, acima de tudo, fruição do material escolhido. Para o docente, além de considerar esses elementos, deve-se pensar, ainda, em como propiciar o cruzamento das habilidades de língua a serem evidenciadas dentro do nível do grupo.

Tendo feito esse preâmbulo, cumpre-nos dizer que, neste trabalho, aventamos lançar olhares sobre a literatura em aulas de língua inglesa (LI) voltadas para a formação do professor. Este texto nasce, pois, de (des)encontros. Expliquemo-nos. A primeira autora trabalha há mais de dez anos com disciplinas de estágio supervisionado em LI; o segundo ministra disciplinas de literatura em LI por cerca de 20 anos. Além da convergência do lugar que ocupamos na academia - o de formadores de professores de LI -, compartilhamos também algumas inquietações no que diz respeito ao trabalho com a leitura. Assim, se, por um lado, nos encontramos para refletir sobre o ensino-aprendizagem de leitura, no contexto de formação de professores de LI, a partir da discussão de propostas pedagógicas voltadas para a abordagem do texto literário; por outro, somos provocados pela percepção de que o objetivo que aqui nos propomos caminha em direção oposta ao que comumente se vê nas licenciaturas.

"Em cada linha que escrevo trato sempre, com maior ou menor fortuna, de invocar os espíritos esquivos da poesia", disse o escritor colombiano Gabriel García-Márquez, em seu discurso ao Nobel, em 1982 (GARCÍAMÁRQUEZ, 2016, p. 13). Esse pensamento, incitando a busca no espírito da imaginação e entrelaçado à sombra da realidade, leva-nos a um questionamento cuja inquietude se revela no modo como a relação entre o ler, o escrever e o interpretar tem soado dissonante, especialmente no que tange à formação docente neste e em outros países.

Ora, se o ato de escrever (literariamente) é produzido com o auxílio "espiritual", transcendente da poesia (leia-se da arte e da estética), é essencial inserir tal produção no universo do futuro docente, como parte de sua instrumentalidade para seu próprio repertório de conhecimento e de ensino. Obviamente sentimos cada vez mais que a realidade universitária, de forma geral, parece se imiscuir da obrigatoriedade de conectar currículos promotores de uma formação mais ampla e abrangente aos discentes, e o caso língua/literatura compõe uma dessas dicotomias abordadas por teóricos de várias áreas.

Nos currículos universitários, mesmo em termos de planejamentos e competências, parece não haver a comunhão entre o empirismo da leitura literária com a prática da língua entre os discentes, futuros professores. Há uma dissonância abissal entre um objetivo ideal de congruência entre leitura e prática de língua e os caminhos estáticos apresentados pela realidade.

Dessa forma, para que a reflexão almejada neste artigo seja possível, partimos da desconstrução de algumas dicotomias que parecem perpassar discursividades acerca da formação de professores de LE, bem como os currículos dos cursos de Letras. Referimo-nos à polarização entre língua/literatura e entre aprender língua/aprender a ser professor de língua, a qual nos convoca a levantar dois questionamentos: como ensejar práticas de leitura na universidade que possibilitem ao licenciando trabalhar o texto como materialidade linguístico-discursiva, por meio da qual ele possa se constituir leitor e (futuro) professor? E de que forma o trabalho com o texto literário pode contribuir para tal processo? Nossa discussão, longe de esgotar a discussão sobre a presente dicotomia, se delimita a algumas considerações sobre o currículo de um curso de Letras/Inglês, em uma universidade pública, no interior de Minas Gerais e sobre uma experiência com textos literários, em uma disciplina voltada para o desenvolvimento da leitura em LI, na referida instituição. 
No intuito de lançar luz a essas indagações, iniciamos com algumas ponderações sobre a configuração da literatura no currículo do referido curso de licenciatura, no qual atuamos. Em seguida, discutimos o ensinoaprendizagem de leitura em LI, de forma a explicitar as noções de linguagem, texto, leitor e literatura que balizam o nosso olhar. Apresentamos, então, algumas experiências com o texto literário, vivenciadas em uma disciplina de leitura em LI. Finalmente, tentamos alinhavar alguns fios, no intuito de contribuir para apontar vias outras que não a da dicotomização.

\section{LITERATURA E A FORMAÇÃO DO PROFESSOR DE LI: OLHARES PARA UMA LICENCIATURA}

O Curso de Licenciatura em Letras-Inglês no qual atuamos passou por recente mudança curricular, sendo que até 2018 o discente entrava para o Curso de Letras e fazia a opção pela habilitação em uma língua (inglês, português, espanhol ou francês), ao término do primeiro ano. A partir de 2018, as habilitações foram desmembradas em cursos independentes.

No Projeto Pedagógico do Curso (PPC), lê-se que

Também a Literatura sofreu mudanças nos seus paradigmas de análise. Abandonou a abordagem meramente periodista e passou a ocupar-se com o estudo das diferentes organizações discursivas e textuais das obras literárias, a partir de perspectivas variadas, tais como: a filosófica, a histórica, a semiótica, entre outras. (PPC, 2017, p. 21)

Ainda que haja menção ao abandono da periodização literária no novo currículo, o PPC traz à baila a abordagem tradicional no ensino de literatura, tanto na formação básica como na formação do professor, acenando para a necessidade de se distanciar dela, ao favorecer um trabalho com o literário que abranja sua relação com outras áreas do saber, o que percebemos não ocorrer em termos de ensino de língua.

Lopes, Costa e Sampaio (2011), ao analisarem ementas de disciplinas voltadas para literatura, em um curso de Letras/Português, apontam a ausência do trabalho com o letramento literário em contraposição à ênfase no estudo da periodização literária. As autoras refutam a ideia de um modelo de ensino de literatura, mas fazem a seguinte provocação:

se as teorias atuais sobre ensino de literatura se baseiam primeiro na leitura do texto literário, é contraditório que a maioria esmagadora das disciplinas se fundamente em leituras sobre contextos históricos. As literaturas são vistas com características, estilo, estudo de autores e obras que parecem estar no cânone. O tradicionalismo da periodização toma conta das disciplinas obrigatórias do início ao fim. Como mudar isso na prática a partir do estágio supervisionado e, logo após, nas escolas onde o professor, já formado, irá trabalhar? (LOPES; COSTA; SAMPAIO, 2011, p. 79)

Os questionamentos de Lopes, Costa e Sampaio (2011) apontam para a existência de um ciclo vicioso de abordagem da literatura, por meio do qual universidade e escola tendem a se esquivar de promover experiências com o texto literário em prol de estudos históricos e biográficos, abrindo, quando muito, espaço para o estudo do obras canônicas.

França (2019) também defende a necessidade de se ensejarem práticas de letramento literário capazes de construírem "um olhar-outro para literatura na escola" (p. 93). O autor defende que o texto literário seja abordado como manifestação discursiva capaz de contemplar a realidade dos alunos. Para isso, ele explora o conceito de empoderamento literário", definido "como um ato sócio-político-formativo e emancipatório em que o sujeito, por meio da linguagem literária, é interpelado a se inscrever e participar, de maneira responsiva-responsável, de diferentes práticas sociais" (FRANÇA, 2019, p. 98).

França argumenta que a escassa quantidade de trabalhos acadêmicos de graduação voltados para o ensino da literatura confirma que o foco da universidade e dos cursos de Letras recai muito mais na formação de pesquisadores e acadêmicos "que se voltam para a literatura a partir do seu inquestionável valor estético e, raramente, enquanto objeto que pode e deve ser, de maneira responsável, escolarizado". (FRANÇA, 2019, p. 92). Fazemos coro com os posicionamentos desse autor por entendermos que os cursos de licenciatura não podem se furtar a oferecer, ao professor em formação, experiências nas quais o texto literário seja abordado como objeto de ensino, ainda que não se reduza a ele.

4. A proposta de França (2019) se baseia na interface teórica entre a Linguística Aplicada indisciplinar, proposta por Moita Lopes, a Análise do Discurso de Michel Pêcheux e os estudos bakhtinianos. 
A dicotomia língua/literatura presente nas licenciaturas de Letras voltadas para a língua portuguesa, como nos mostram os trabalhos acima, tende a ser reforçada nos cursos voltados para a LE, haja vista o nível de proficiência linguística dos licenciandos. Daí é comum serem recorrentes questões como: de que forma trabalhar textos literários na língua original se os discentes são aprendizes em fase inicial na LE? Ou: para que trabalhar o ensino da literatura inglesa se não há aulas de literatura inglesa na educação básica? Entendemos que essas questões precisam ser problematizadas (e respondidas) a partir de uma formação que permita ao licenciando constituir-se leitor-professor de textos literários.

No intuito de identificar possíveis momentos de convergência entre literatura e ensino, em nosso currículo, buscamos, nas ementas do PPC, todas as menções à literatura ou ao texto literário, a fim de refletir em que medida a proposta curricular de fato abandona uma ênfase na periodização e considera possibilidades outras de trabalho. Observamos que tais termos estão presentes apenas nos componentes curriculares voltados à literatura, não havendo, pois, qualquer menção a eles em disciplinas de língua, linguística ou linguística aplicada. Entendemos que a ementa não garante a prática do professor formador, isto é, o fato de as ementas não contemplarem a relação ensino/ literatura não impede que propostas com o texto literário sejam abordadas por um viés mais pedagógico. Contudo, a formalização (ou não) dessa relação no PPC parece ressoar uma memória que coloca o estudo da língua em oposição, ou distanciamento, ao estudo da literatura.

O currículo em análise conta com oito disciplinas de literatura e um módulo 5 em Estudos Literários, no qual é oferecido um leque de disciplinas, conforme demanda e interesse de discentes e docentes. No Quadro 1, abaixo, apresentamos as disciplinas com as referidas ementas.

\section{Quadro 1. Disciplinas de Literatura na Licenciatura Letras/Inglês.}

\begin{tabular}{|c|c|}
\hline Disciplina & Ementa \\
\hline $\begin{array}{l}\text { Teoria da Literatura I } \\
1^{\circ} \text { período }\end{array}$ & Questões gerais de teoria literária. Teoria e análise do texto narrativo. \\
\hline $\begin{array}{l}\text { Teoria da Literatura II } \\
2^{\circ} \text { período }\end{array}$ & A questão dos gêneros literários. Teoria e análise de textos poéticos. \\
\hline $\begin{array}{l}\text { Estudos Clássicos: } \\
\text { Introdução à Literatura } \\
\text { Latina } \\
3^{\circ} \text { período }\end{array}$ & $\begin{array}{l}\text { Introdução ao mundo clássico antigo. notadamente o greco-romano, com ênfase na história } \\
\text { e literatura romanas. Visão panorâmica da Literatura latina por meio da leitura de traduções e } \\
\text { análise dos modelos de construção de obras selecionadas de autores fundamentais. }\end{array}$ \\
\hline $\begin{array}{l}\text { Literatura Inglesa: das } \\
\text { Origens ao Renascimento } \\
4^{\circ} \text { período }\end{array}$ & $\begin{array}{l}\text { Estudo das origens da língua inglesa; estudo das formas artísticas que antecedem e influenciam } \\
\text { a literatura em inglês moderno; estudo da obra em inglês antigo (Old English); estudo da obra em } \\
\text { inglês medieval (Middle English); Chaucer; estudo da obra no período inicial do inglês moderno } \\
\text { (Early Modern English); Shakespeare e seus contemporâneos. }\end{array}$ \\
\hline $\begin{array}{l}\text { Literatura Inglesa: } \\
\text { Iluminismo e Romantismo } \\
5^{\circ} \text { período }\end{array}$ & $\begin{array}{l}\text { Estudo do Iluminismo e seus precursores; estudo do Romantismo e seus precursores; o romance } \\
\text { e a poesia oriundos do Iluminismo; origens do termo "romântico" e as características estéticas e } \\
\text { literárias do romantismo; os valores culturais da sociedade europeia; os fatos sociais, econômicos } \\
\text { e históricos que marcaram o iluminismo e movimento romântico da literatura inglesa. }\end{array}$ \\
\hline $\begin{array}{l}\text { Literatura Inglesa: } \\
\text { do Vitorianismo ao } \\
\text { Contemporâneo } \\
7^{\circ} \text { período }\end{array}$ & $\begin{array}{l}\text { Estudo das obras literárias características dos períodos que vão do século XIX ao presente; } \\
\text { contexto das obras do período vitoriano e situação das questões emergentes e mudanças } \\
\text { ocorridas na sociedade inglesa com a ascensão da Rainha Vitória; contexto da modernidade e a } \\
\text { pós-modernidade na sociedade inglesa considerando as novas tendências estéticas ocorridas na } \\
\text { literatura do século XX até o momento atual bem como as transformações sociopolítico-culturais } \\
\text { desse período, os conflitos identitários, religiosos, culturais e de cunho filosófico. }\end{array}$ \\
\hline $\begin{array}{l}\text { Literatura Norte- } \\
\text { Americana: do Realismo } \\
\text { ao Contemporâneo } \\
8^{\circ} \text { período }\end{array}$ & $\begin{array}{l}\text { Estudo do surgimento do realismo, do modernismo, e pós-modernismo; estudo da relação entre } \\
\text { literatura e as novas formas artísticas do século XX e XXI. }\end{array}$ \\
\hline
\end{tabular}

5. Os módulos se referem a componentes curriculares agrupados sob temáticas específicas tratadas no curso. Segundo o PPC, a oferta dos componentes em módulos "constitui avanço na estrutura curricular, porque permite que a oferta seja sempre diversificada, o que enriquece a formação dos licenciandos em relação a seus interesses de estudos". (PPC, 2017, p. 30). 


\begin{tabular}{|c|c|}
\hline $\begin{array}{l}\text { Estudos Literários: } \\
\text { Tendências Críticas } \\
8^{\circ} \text { período }\end{array}$ & Estudos literários: tendências contemporâneas da crítica literária; literatura e educação ambiental. \\
\hline \multicolumn{2}{|r|}{$\begin{array}{l}\text { Componentes Curriculares do Módulo em Estudos Literários } \\
\qquad 6^{\circ} \text { período }\end{array}$} \\
\hline Disciplina & Ementa \\
\hline Literatura e História & $\begin{array}{l}\text { Estudo da relação entre a literatura e história; movimentos literários; grandes eventos históricos } \\
\text { e seus impactos. }\end{array}$ \\
\hline Literatura Fantástica & $\begin{array}{l}\text { Estudo do fantástico e suas vertentes; estudo do gótico, do maravilhoso, do realismo mágico, da } \\
\text { ficção científica, do estranho, da fantasy. }\end{array}$ \\
\hline Literatura e Outras Artes & $\begin{array}{l}\text { Estudo da relação entre a literatura e outras formas de arte; literatura e música; literatura e artes } \\
\text { visuais; literatura e fotografia, literatura e cinema. }\end{array}$ \\
\hline $\begin{array}{l}\text { Literatura em Língua } \\
\text { Inglesa: Minorias Estéticas }\end{array}$ & $\begin{array}{l}\text { O estudo do conceito de Minorias na relação cultura/língua/estética, contemplando estudos } \\
\text { de gênero, raça, sexualidade e etnia; do significado da diferença e sua influência na produção } \\
\text { literária; do advento da estética e de identificação político-cultural; dos conflitos de valor da } \\
\text { linguagem das minorias e de sua produção literária, a partir dos gêneros drama, poesia e narrativa } \\
\text { dessas minorias. }\end{array}$ \\
\hline Escrita Criativa & $\begin{array}{l}\text { Estudo da escrita criativa através da composição literária; estudo da oficina literária como } \\
\text { instrumento pedagógico de produção de textos; estudo da relação entre literatura e a } \\
\text { institucionalização da Escrita Criativa. }\end{array}$ \\
\hline $\begin{array}{l}\text { Literaturas de Expressão } \\
\text { em Língua Inglesa }\end{array}$ & $\begin{array}{l}\text { Estudo crítico-analítico de obras pertencentes às literaturas escritas em Língua Inglesa; as } \\
\text { especificidades históricas, sociais, culturais, políticas, estéticas, psicológicas, filosóficas e } \\
\text { religiosas observadas nessas literaturas de diversos contextos, tempos e espaços. }\end{array}$ \\
\hline
\end{tabular}

Fonte: PPC, 2017.

Como se pode observar, no Quadro 1, a periodização ainda se constitui como o eixo norteador do currículo, sendo que uma maior abertura se concentra nas disciplinas de Módulo. Em termos gerais, o foco parece recair sobre a apreciação estética, ancorada na análise e teoria literárias. Além disso, com exceção dos componentes curriculares Escrita Criativa, que contempla o "estudo da oficina literária como instrumento pedagógico de produção de textos"; e na disciplina Estudos Literários: Tendências Críticas, cuja ementa apresenta "literatura e educação ambiental", não há qualquer menção ao ensino de literatura, o que nos leva a afirmar que a dicotomia língua/literatura ainda prevalece no currículo.

Assim, tendo em vista que a ementa é um dos elementos mais relevantes de uma ficha de disciplina, lamentamos o fato de elas não contemplarem essa relação com o ensino de língua já em sua base. Ainda que o professor formador possa alegar que o ensino da língua é pressuposto, a tendência é que haja abordagem estritamente ao trabalho com o texto literário, e não o cruzamento deste com os elementos linguísticos ou mesmo estratégias de ensino de língua, pois, em muitos casos, o formador pode passar ao largo dessas estratégias, seja por divergências/crenças teóricas, seja por receio do confronto com o ensino de língua, com o qual ele pode não ter tanta afinidade.

\section{LINGUAGEM, LEITURA (LITERÁRIA) E FORMAÇÃO DO PROFESSOR}

Em trabalhos anteriores, discutimos a importância de se recusar noções tecnicistas de formação em favor de uma formação que contemple aspectos identitários, discursivos, políticos, ideológicos, sociais, culturais, enfim uma rede de elementos que entra em cena no complexo processo de se formar um professor (BRITO, RIBAS, 2019; BRITO; GUILHERME, 2017). Tal visão se respalda sobretudo nos estudos indisciplinares e transgressivos da Linguística Aplicada (MOITA LOPES, 2006), para os quais a formação do professor é, antes de tudo, uma tomada política de posição (SZUNDY, 2014), processo de (trans)formação e forma(r)-ação (GUILHERME, 2017). Ademais, interessa-nos pensar uma formação que não dissocie a aprendizagem da língua estrangeira do processo mesmo de se constituir professor dessa língua. Ou seja, não se trata de primeiro ensinar uma língua, e depois de se ensinar a ensiná-la; antes, entendemos que 
a própria formação docente deve promover formas de tomada da palavra, isto é, de possibilidade de se inscrever subjetivamente na e pela língua e poder produzir sentido, e de reflexão sobre a/pela língua, a qual, para esse sujeito, se constitui tanto como objeto de estudo quanto como materialidade significante (BRITO; HASHIGUTI, 2019, p. 109).

A dicotomia aprender lingua/aprender a ser professor de lingua funciona discursivamente de forma a deslegitimar o curso de Letras como lugar para se aprender a língua inglesa. Nessa mesma esteira, Brito e Guilherme (2014) investigam representações discursivas sobre língua (estrangeira), processo de ensino-aprendizagem, sujeito-aluno e sujeitoprofessor, presentes em memoriais de aprendizagem escritos por professores pré-serviço de línguas estrangeiras. O referido estudo aponta que, nos dizeres dos sujeitos enunciadores, estabelece-se uma dicotomia entre 'escolas regulares e curso de Letras na universidade', tidos como não lugares de aprendizagem de inglês e 'institutos particulares de idiomas', vistos como lugares legítimos de aprendizagem de inglês no Brasil. As representações se ancoram nos discursos da ausência e da falta, balizados pelo desejo de uma proficiência idealizada na língua inglesa, e na concepção de que o foco do curso de Letras seria a formação do professor (e não a aprendizagem da língua).

Assim, parece haver uma memória cristalizada, constituinte das discursividades produzidas no âmbito das licenciaturas, que reforça o imaginário de que o único espaço legítimo para se aprender a LE são os institutos de idiomas. A nosso ver, a não problematização dessa dicotomia pode impedir que o professor em formação experiencie modos outros de entrada (e, portanto, de enunciação) na língua que ensina-aprende. Modos esses que precisam possibilitar-lhe dizer(-se) na e sobre a LI e não apenas "manejá-la" como mero instrumento de comunicação.

Portanto, para que haja solidez num diagnóstico efetivo dessa disparidade e dissociação entre ler literatura e utilizá-la de maneira mais efetiva em sala de aula de língua, é preciso antes considerar conceitos, tais como o de texto, cujo escopo tem transcendido a palavra escrita em papel nas últimas décadas e entrado em outras; o de literatura, calcado em modelos tradicionais, mas focando em uma comunhão entre mídias e diversos suportes convergindo num texto composto de elementos além das palavras na contemporaneidade; e o de leitor, cuja função tem sido muito mais determinante e atuante no sentido a dar validade à interpretação daquilo que se chama texto.

Nessa esteira de definições, é interessante trazer à tona a assertiva de Clüver (2006, p. 15), para quem a noção de texto ganha elasticidade, em especial a obra de arte; possivelmente, para além da genérica afirmação de que "tudo é texto". Aqui, percebe-se que o teórico, ao tratar do conceito, remete-se à intertextualidade e realiza pontes entre os textos possíveis provenientes da imagem, do som, das mídias em geral, e obviamente, da palavra:

Portanto, um balé, um soneto, um desenho, uma sonata, um filme e uma catedral, todos figuram como "textos" que se "leem"; o mesmo se pode dizer de selos postais, uma procissão litúrgica e uma propaganda na televisão. Contra essa ampliação do conceito de "texto" na perspectiva semiótica foi levantada a objeção de que ela conduziria a uma supervalorização do modelo linguístico, especialmente em associação ao ato de "ler" (em sentido expressamente metafórico). Por experiência própria, penso que isso é uma questão de hábito e que a palavra "texto", na aplicação intertextual, rapidamente se torna um conceito neutro. (CLÜVER, 2006, p. 15. Grifos do autor)

Ou seja, a transcendência de sentido para o conceito de texto apresenta-se auspiciosa para demonstrar que a construção de sentido pode ser lida em muitos outros suportes - seja no filme, seja no quadro, no disco, na animação, na narrativa gráfica, dentre outros, partindo do pressuposto de que todos estes são, no fim das contas, textos. Portanto, o texto está circunscrito na Mona Lisa, nos traços de Alan Moore, nos movimentos de Deborah Colker, e também na produção em papel dos gênios literários (canônicos ou não) ao longo da história da escrita, e em muitos outros possíveis suportes artísticos.

Sucede-se a essa definição, ainda que rasa, de texto, a de literatura. Essa, talvez um tanto mais complexa, poderia ser simplificada a partir do que Terry Eagleton (1985) nos dá ao afirmar que a literatura, em resumo, é um construto a ser desenvolvido pelo leitor, partindo de pressupostos essenciais como experiência, repertório, valor, e contexto, e esses elementos, em maior ou menor grau, irão delinear o que o receptor dissecará em sua interpretação. Compagnon (1999), também na esteira de Eagleton, discute em sua obra O demônio da teoria, as relações entre literatura e: intenção, recepção, língua, história e valor literários, na busca de uma definição do que seja, de fato, o que se entende por literatura. De certa forma os dois teóricos começam a desvelar uma nova forma de lidar com o literário a partir da apreciação de várias linguagens, não somente a escrita, uma vez que o que se entendia por literatura até então era o chamado cânone, as obras cristalizadas ao longo do tempo.

Seja como for, literatura na atualidade não pode ser, de maneira alguma, deslocada de uma nova realidade vigente, introjetada de uma grande gama de suportes. Ela ganha, outrossim, uma nova roupagem em termos de corpus e novas redefinições ao entrecruzar com novas possibilidades de produção, de interpretação e de ensino. 
Cabe-nos pensar, ainda, como se define a figura do leitor em tempos atuais. Partindo do pressuposto de que a interpretação subjetiva é largamente incentivada pelos autores acima citados, o ato interpretativo parece ter ganho ainda mais evidência nas últimas décadas, quando se deixa de lado uma interpretação meramente calcada na intencionalidade do autor/produtor para que se foque no repertório de experiências do leitor. Assim, este passa a ter respeitada a sua posição frente ao texto e à obra de arte, considerando-se a sua experiência e o valor, dentre outros aspectos.

Lembremos de Umberto Eco (1962), ao afirmar que a obra de arte é um mecanismo vivo, que depende do olhar do leitor para que faça sentido; além disso, ainda segundo Eco, é fundamental que entendamos que a interpretação da obra não se fecha em si, daí a expressão "obra aberta" como síntese de que é válida a tentativa de interpretação realizada pelo leitor, ainda que a intencionalidade seja desconsiderada.

Zilberman (2017) vai tecer considerações sobre o ato da leitura e tocar na questão do leitor resgatando a estética da recepção, afirmando que Hans Robert Jauss, teórico da recepção

trata de conferir relevância ao público, que acolhe ou não obras do passado e do presente, evidenciando a trajetória de um produto artístico no meio social, avesso via de regra à inovação e submisso à repetição de clichês e fórmulas fáceis. A Estética da Recepção não ignora a indústria cultural, nem a literatura de massa, mas Jauss a rejeita com um piparote, afastando-se, com isso, da Sociologia da Leitura, praticada amplamente em sua terra e em terras alheias, o que lhe permite concentrar-se nas obras renomadas e clássicas, consagradas pela tradição. ZILBERMAN (2017, p. 08)

É daí, portanto, que nascem os primeiros laivos de transferência de responsabilidade ao leitor, pois este terá que lidar com os mecanismos do texto e dar-lhe o sabor de sua experiência. Zilberman ainda chama a atenção para Iser (1996), autor da expressão "leitor implícito", aquele que lida com o texto de modo a potencializar e (re)atualizar seu sentido. Percebemos, assim, que tem havido uma preocupação em se considerar o diagnóstico dado pelo leitor à obra literária, cada vez menos apegada à sua "aura", como afirmou Benjamin em princípios do século passado.

No bojo dessas considerações, está uma concepção de linguagem como prática social, dialógica, situada, marcada histórica e ideologicamente, e constituída nos processos de interação verbal. A nosso ver, é também uma noção de linguagem que sustenta o distanciamento da literatura como possibilidade para a aprendizagem de uma língua outra. Mota (2010), com base no trabalho de Brun (2004), argumenta que a ausência da literatura no ensino de LI se deve, em grande parte, à ênfase dada à abordagem comunicativa, a qual privilegia a instrumentalidade da língua, priorizando situações funcionais, "dá-se especial relevo ao caráter pragmático da língua, o que é extensivo ao tipo de material utilizado para ensiná-la" (MOTA, 2010, p. 104).

Hall (2015), por outro lado, argumenta que a abordagem comunicativa favoreceu a inserção da literatura na sala de aula de LE, justamente por priorizar o uso da língua, a exposição dos aprendizes a materiais autênticos, bem como por promover a aquisição de vocabulário, encorajar o pensamento crítico e desenvolver competências interculturais. O autor, todavia, deixa claro que o trabalho com o texto literário foi (e ainda é) marcado por visões conflitantes, mais ou menos entusiastas, e baseadas em diferentes visões do lugar da literatura no ensino-aprendizagem de línguas. Em suas palavras,

Nos países 'do centro' de ensino de língua inglesa (Reino Unido, Estados Unidos etc.), no paradigma comunicativo dominante, o ensino de literatura em contextos de segunda língua geralmente não é sistemático, nem bem integrado e, muitas vezes, periférico. A linguagem do texto em si é considerada incidental e não é um foco de atenção, exceto por algumas abordagens estilísticas mais formalistas ou (muitas vezes) por uma obsessão míope pelo vocabulário. (HALL, 2015, p. 124. Grifo do autorø).

Tradicionalmente, a literatura voltada para o ensino-aprendizagem de línguas estrangeiras se pauta na noção herdada do audiolingualismo (KUMARAVADIVELU, 2003) de que há quatro habilidades (skills) a serem trabalhadas, a saber: audição, leitura, fala e escrita, sendo as duas primeiras tidas como habilidades produtivas e as duas últimas, receptivas. Apesar de outras visões virem sendo apropriadas nos processos pedagógicos e de elaboração de material didático, a organização de livros didáticos em torno dessas habilidades ainda é muito comum ${ }^{7}$.

6. Nossa tradução do original: "In the 'Centre' English teaching countries (the United Kingdom, the United States, etc.), in the dominant communicative paradigm, the teaching of literature in second language contexts is typically not systematic, not well integrated, and often peripheral. The language of the text itself is considered incidental and is not a focus of attention except for some more formalist stylistic approaches or (often) a myopic obsession with vocabulary". (HALL, 2015, p. 124).

7. Aliás, o desenvolvimento de habilidades aparece como um dos eixos norteadores da Base Nacional Comum Curricular (BNCC), como se pode ver em Brasil (2017). 
Ao defender o trabalho com a leitura do texto literário em sua relação com o ensino da língua inglesa como processo que pode ensejar momentos significativos de tomada da palavra na língua outra, incidindo, assim de forma produtiva na e para a formação do professor, ancoramo-nos em uma visão que refuta qualquer caráter de passividade ou estaticidade da leitura, como se esta consistisse na mera extração de mensagens em um texto ou na identificação de sentidos já presentes ali.

Antes, pautamo-nos na concepção de leitura como processo sócio-historicamente situado, determinado por suas condições de produção, as quais envolvem o contexto imediato (gênero discursivo, relação entre interlocutores, tema do texto, status do autor etc.) e outro mais amplo, referente ao contexto sócio-histórico e ideológico. Entendemos, pois, que ler implica uma réplica, em sentido bakhtiniano, isto é, em uma tomada de posição. Nas palavras de Bakhtin $(1979 / 2000)$,

De fato, o ouvinte que recebe e compreende a significação (linguística) de um discurso adota simultaneamente, para com este discurso, uma atitude responsiva ativa: ele concorda ou discorda (total ou parcialmente), completa, adapta, apronta-se para executar, etc., e esta atitude do ouvinte está em elaboração constante durante todo o processo de audição e de compreensão desde o início do discurso, às vezes já nas primeiras palavras emitidas pelo locutor. A compreensão de uma fala viva, de um enunciado vivo é sempre acompanhada de uma atitude responsiva ativa (conquanto o grau dessa atividade seja muito variável); toda compreensão é prenhe de resposta e, de uma forma ou de outra, forçosamente a produz: o ouvinte torna-se o locutor. (BAKHTIN, 1979/2000, p. 290. Grifos do autor)

As considerações de Bakhtin vão ao encontro da noção de letramento crítico, que recusa o conceito de leitura como mera habilidade técnica individual de decodificar sinais gráficos, bem como uma visão de neutralidade e abstração em relação ao ato de ler. Antes, entende-se que ler consiste em uma prática social, situada, concreta, perpassada pelos embates ideológicos e pelas relações de poder que constituem as relações humanas. Ler implica, assim, na compreensão de como os enunciados se relacionam a outros enunciados ditos anteriormente, no processo dialógico da interação verbal, por meio do qual a tomada da palavra vem sempre com uma acentuação valorativa.

Ademais, o letramento crítico tem a ver com a necessidade de se assumir um lugar ético no mundo, em que o sujeito se responsabiliza pela leitura que faz, nos termos de Menezes de Souza (2011). O autor defende que o

Letramento crítico consiste em não apenas ler, mas ler se lendo, ou seja, ficar consciente o tempo inteiro de como eu estou lendo, como eu estou construindo significado... e não achar que leitura é um processo transparente, o que eu leio é aquilo que está escrito... Pensar sempre: por que entendi assim? Por que acho isso? De onde vieram as minhas ideias, as minhas interpretações? (MENEZES DE SOUZA, 2011, p. 296. Grifos do autor).

As considerações de Menezes de Souza problematizam a relação texto-leitor, apontando o inevitável caráter de implicância que aí se estabelece, haja vista serem, a seu ver, o dissenso e o conflito as metáforas para a leitura. Isto é, na inexistência do sentido único, universal, estático, cabe ao leitor tomar posição frente ao que lê, imprimindo ao texto sua "atitude responsiva ativa".

Em relação à afirmação do autor acerca de que é preciso "ficar consciente o tempo inteiro de como eu estou lendo", arriscaríamos algumas provocações: é possível ao sujeito, perpassado pelo inconsciente, constituído na/pela linguagem, ter um controle (total) sobre o processo de sua leitura? Não haveria sempre aí algo que (lhe) escapa, da ordem do não-controle, do inacabamento, da inconclusibilidade? Poderíamos aventar o letramento crítico como o "ler se lendo", mas também como deixar-se ser lido enquanto se lê?

Nossos questionamentos se baseiam na noção de experiência em Larrosa (2011), definida como "isso que me passa" (LARROSA, 2011, p. 5). Para ele, a experiência tem natureza formativa e transformadora e supõe o princípio da alteridade, da irrepetibilidade, da singularidade. Dito de outro modo, a experiência nos remete a possibilidades de afetar e ser afetado por acontecimentos, de (des)arranjar conceitos e subjetividades, de mobilizar uma outra relação com o saber. No que concerne à experiência da leitura, trata-se de compreender que

o texto tem que ter algo de incompreensível para mim, algo de ilegível /.../ desde o ponto de vista da experiência, não é qual é o livro, mas o que nos passa com sua leitura /.../ Um leitor que, após ler o livro, se olha no espelho e não nota nada, não lhe passa nada, é um leitor que não fez nenhuma experiência (LARROSA, 2011, p. 9).

É, pois, uma visão de literatura como possibilidade de promover a experiência que trans-forma que apostamos no trabalho com o texto literário. Ademais, entendemos que a problematização das dicotomias língua/literatura $e$ aprender língua/aprender a ser professor de lingua pode abrir espaço para que o professor em formação experiencie práticas de linguagem nas quais enuncie em uma língua outra e não apenas estude teorias (linguísticas, literárias, pedagógicas) que supostamente serão implementadas em seu (futuro) fazer docente. Em outras palavras, não se trata de reduzir as 
aulas de literatura à metodologia de ensino, tampouco de negar a importância de outros gêneros discursivos nas aulas de línguas. Antes, defendemos a instauração de diálogos que permitam, ao professor em formação, dizer(-se) na/pela língua que ensina-aprende. A nosso ver, o texto literário se apresenta como corpus privilegiado para essa tomada de posição na/pela língua outra, em níveis ainda iniciais de aprendizagem, e para a problematização de concepções de leitura como mera decodificação, comumente adotadas sobretudo em aulas de línguas estrangeiras.

Enfim, é nessa teia de conceitos (por vezes, desencontrados) que nos balizamos para problematizar a dicotomia leitor em/para formação, e tentar apontar direcionamentos para um diálogo mais profícuo entre ensinar/ler língua/ literatura em um curso de Letras-Inglês.

\section{EXPERIÊNCIAS COM O TEXTO LITERÁRIO EM UMA DISCIPLINA DE LEITURA EM LI}

O lugar de formadores de professores de LI nos permite constatar que, quando demandados a desenvolverem propostas de aulas de leitura, os professores em formação frequentemente se restringem a elaborar atividades voltadas para a mera discussão de temas, com base em um texto motivador, pouco explorando o texto enquanto materialidade linguístico-discursiva que reclama sentidos. Não é raro que propostas de letramento crítico por vezes se restrinjam à abordagem de temáticas polêmicas, por exemplo, cuja discussão se dá prioritariamente na língua materna. Assim, se, por um lado, podemos afirmar que os currículos têm se distanciado de práticas de ensino meramente estruturais, que pouco dizem aos alunos; por outro, a abordagem do texto em si ainda parece ser uma fonte de dificuldades.

A partir dessas inquietações e buscando responder aos questionamentos que levantamos na introdução deste artigo, apresentamos aqui alguns exemplos de trabalho com o texto literário desenvolvidos na disciplina Língua inglesa: babilidades integradas com ênfase na leitura ${ }^{8}$, oferecida no quarto período do curso de Letras/Inglês, cuja ementa se pode visualizar no Quadro 2:

\section{Quadro 2. Ementa da disciplina de leitura.}

Esta disciplina tem seu foco predominante no desenvolvimento da habilidade de leitura em Língua Inglesa, embora as demais habilidades não sejam dispensadas. São trabalhados os conhecimentos estratégicos pertinentes ao processo de leitura, textual, de mundo, atitudinal e sistêmico, de forma a possibilitar a inserção e participação comunicativa dos alunos em relação aos gêneros discursivos, nas suas dimensões textual e discursiva, que permeiam sua vida pessoal, profissional e acadêmica tanto em contextos presenciais como nos mediados pelas novas tecnologias.

Fonte: PPC, 2007.

Como se pode observar, a ementa da disciplina traz a questão dos gêneros discursivos como fio condutor para se trabalhar conhecimentos linguísticos e comunicativos no intuito de desenvolver a proficiência leitora do professor em formação. Apesar de não haver referência a textos literários, cremos que a ementa abre espaço para uma variedade de gêneros e possibilidades de trabalho com a leitura. Ademais, entendemos que a esfera literária permeia a vida profissional e acadêmica do licenciando em Letras, por meio do estudo e abordagem de gêneros diversos, tais como: poesia, prosa, contos, romances, peças, narrativas gráficas, letras de música, dentre outros.

A disciplina foi ministrada no segundo semestre de 2018 e contava com cerca de doze discentes com nível de inglês entre intermediário e avançado. Toda a disciplina foi organizada de forma a mesclar discussões teóricas ${ }^{9}$ sobre a leitura (e seu ensino) e atividades de interpretação de textos, propriamente ditas. O intuito era, pois, permitir que o professor em formação desenvolvesse práticas de compreensão escrita a partir de seu lugar como futuro professor de língua inglesa. Para isso, propusemos, para as aulas teóricas, os seguintes temas: i) leitura: conceitos; ii) ensino de leitura na aula de LE; iii) ensino de LE: letramento e criticidade; e iv) ensino de leitura e tecnologia; e fizemos a análise de diferentes gêneros discursivos e o estudo de aspectos linguístico-discursivos da língua inglesa. Tentamos organizar a discussão dos temas a partir de gêneros acadêmicos, tais como debates e mesas-redondas, sendo os discentes responsáveis pela condução das discussões. Contamos ainda com o Moodle como apoio às aulas presenciais. $\mathrm{Na}$ plataforma virtual, postávamos questões norteadoras para a discussão dos temas em sala de aula, bem como

8. Essa disciplina fazia parte do fluxograma do currículo que passou a vigorar em nossa instituição em 2008. Nesse currículo, como mencionado anteriormente, o discente, após cursar o ciclo básico, optava, ao final do primeiro ano do curso, pela habilitação pretendida (inglês, português, espanhol ou francês). A partir de 2018, as habilitações foram desmembradas em cursos independentes.

9. Os textos teóricos eram também, em sua grande maioria, em língua inglesa. 
atividades complementares ou de fechamento às discussões feitas em sala. Além dos textos acadêmicos, selecionamos notícias, artigos de opinião, poemas e contos que possibilitassem que a prática da leitura fosse explorada de forma a promover a integração da compreensão e produção escrita e oral na língua inglesa.

Para explicitar nossa proposta pedagógica de trabalho do texto literário, selecionamos cinco aulas e as recortamos em três momentos principais, a saber: i) pré-atividade; ii) desenvolvimento; e iii) fechamento.

\begin{tabular}{|l|l|}
\hline \multicolumn{2}{|c|}{ Aula 1: The Oval Portrait, de Edgar Allan Poe } \\
\hline Pré-atividade & $\begin{array}{l}\text { Sem muitas explicações, distribuímos diferentes fragmentos do conto The Oval Portrait aos alunos e } \\
\text { pedimos que escrevessem uma narrativa de forma a dar sentido ao fragmento que receberam. }\end{array}$ \\
\hline Desenvolvimento & $\begin{array}{l}\text { As histórias dos alunos foram compartilhadas com toda a sala e passamos à leitura do conto original } \\
\text { para que eles pudessem comparar suas produções com o conto de Poe. }\end{array}$ \\
\hline Fechamento & Procedemos, então, à discussão das percepções dos alunos sobre o conto e as possíveis interpretações \\
\hline
\end{tabular}

\begin{tabular}{|l|l|}
\hline \multicolumn{2}{|c|}{ Aula 2: Wislawa Szymborska } \\
\hline Pré-atividade & $\begin{array}{l}\text { Iniciamos indagando os alunos sobre o que sabiam sobre Wislawa Szymborska e solicitamos que } \\
\text { pesquisassem sobre ela e compartilhassem com a turma. }\end{array}$ \\
\hline Desenvolvimento & $\begin{array}{l}\text { Após o compartilhamento de informações sobre a poeta, propusemos que os alunos lessem três } \\
\text { poemas (Nothing Twice, Possibilities e Could have) e discutissem suas percepções com diferentes colegas. } \\
\text { Em seguida, pedimos que formulassem perguntas que pudessem ajudar um aluno de língua inglesa a } \\
\text { interpretar os poemas. Fizemos, então, a discussão das perguntas elaboradas pelos discentes. }\end{array}$ \\
\hline Fechamento & $\begin{array}{l}\text { Como fechamento da aula, solicitamos aos alunos que escrevessem um texto de forma a explicitar } \\
\text { como sua interpretação dos poemas se relacionava com os aspectos teóricos acerca do processo da } \\
\text { leitura, discutidos em aula anterior. }\end{array}$ \\
\hline
\end{tabular}

\begin{tabular}{|l|l|}
\hline \multicolumn{2}{|c|}{ Aula 3: The Doll's House, de Katherine Mansfield } \\
\hline Pré-atividade & $\begin{array}{l}\text { Iniciamos indagando os alunos sobre o que sabiam sobre Katherine Mansfield e solicitando que } \\
\text { pesquisassem sobre ela e compartilhassem com a turma. }\end{array}$ \\
\hline Desenvolvimento & $\begin{array}{l}\text { Após o compartilhamento de informações sobre a autora, apresentamos um trecho do conto The } \\
\text { Doll's House e discutimos o que nos era possível conhecer sobre a Doll's House a partir dos comentários } \\
\text { do narrador. Passamos, então, à leitura do conto de forma a confrontar a primeira percepção. }\end{array}$ \\
\hline Fechamento & $\begin{array}{l}\text { Procedemos, em seguida, à discussão das percepções dos alunos sobre o conto e as possíveis } \\
\text { interpretações. }\end{array}$ \\
\hline
\end{tabular}

\begin{tabular}{|l|l|}
\hline \multicolumn{2}{|c|}{ Aula 4: Maya Angelou e Langston Hughes' } \\
\hline Pré-atividade & $\begin{array}{l}\text { Iniciamos a aula indagando os alunos sobre o que sabiam sobre Maya Angelou e Langston Hughes. } \\
\text { Solicitamos que pesquisassem sobre eles e compartilhassem com a turma. }\end{array}$ \\
\hline Desenvolvimento & $\begin{array}{l}\text { Após o compartilhamento de informações sobre os poetas, solicitamos que os alunos lessem os } \\
\text { poemas I, too e Still I Rise e tomassem notas de suas primeiras impressões, bem como de palavras que } \\
\text { julgassem importantes ou que lhes fossem desconhecidas. Eles deveriam, então, compartilhar com } \\
\text { algum colega suas percepções acerca dos temas dos poemas, baseados em suas características (em } \\
\text { termos de imagens, estruturas, tom etc.). Em seguida, solicitamos que fosse feita a leitura em voz alta } \\
\text { dos poemas e discutimos suas semelhanças e diferenças e os estilos dos poetas. }\end{array}$ \\
\hline Fechamento & $\begin{array}{l}\text { Propusemos, como fechamento, a discussão da pergunta: Você acha que esses poemas ainda são } \\
\text { relevantes hoje? Por que (não)? }\end{array}$ \\
\hline
\end{tabular}




\begin{tabular}{|l|l|}
\hline \multicolumn{2}{|c|}{ Aula 5: Multitudes, de Lucy Caldwell ${ }^{2}$} \\
\hline Pré-atividade & $\begin{array}{l}\text { Iniciamos indagando os alunos se sabiam algo sobre a premiação One Dublin, One Book }{ }^{3} \text {, organizada } \\
\text { pelas livrarias de Dublin, a fim de encorajar a população a ler livros relacionados à capital irlandesa } \\
\text { durante o mês de abril. Anunciamos que eles leriam um conto presente na antologia The Long Gaze Back } \\
\text { (collection of thirty stories from writers past and present, from the 18 } \\
\text { diferentes Century to now). Para isso, distribuímos } \\
\text { escrever suas inferências e compartilhá-las com o grupo. }\end{array}$ \\
\hline Desenvolvimento & $\begin{array}{l}\text { Os alunos compartilharam suas inferências e passamos à leitura do conto e a discussão de sua } \\
\text { temática. Em seguida, pedimos para que os discentes lessem algumas resenhas sobre a coletânea, a } \\
\text { fim de exploramos esse gênero. Após a discussão das características do gênero resenha, solicitamos } \\
\text { que os alunos ouvissem uma entrevista sobre o livro e identificassem as semelhanças e diferenças } \\
\text { entre a entrevista e a resenha escrita. }\end{array}$ \\
\hline Fechamento & $\begin{array}{l}\text { Como fechamento da discussão, propusemos que os alunos produzissem um texto com suas } \\
\text { percepções sobre o conto Multitudes, no Moodle, e que dialogassem com seus pares, apontando as } \\
\text { diferenças e/ou semelhanças entre suas percepções. }\end{array}$ \\
\hline
\end{tabular}

Sem a pretensão de pleitear qualquer caráter de novidade para as propostas desenvolvidas, ressaltamos aqui suas possíveis contribuições para a aproximação entre língua, literatura e ensino, tendo em vista a formação do professor. Assim, em termos gerais, acreditamos que elas: permitiram experiências variadas de se abordar um texto literário, tendo em vista a aprendizagem da $\mathrm{LE}_{\text {; }}$ abriram espaço para a escrita criativa, bem como para a integração de outras habilidades; demandaram a mobilização de conhecimentos linguísticos para interpretar os textos (e darlhes, por exemplo, uma coesão e coerência para reconstruir a narrativa proposta ou inferir seu tema); exploraram a materialidade linguístico-imagética-sonora dos textos, por meio da análise de imagens, metáforas, voz narrativa, tema etc; promoveram a tomada de posição na língua alvo; mobilizaram e expandiram o horizonte cultural ${ }_{\text {; }}$ propiciaram a articulação entre o processo interpretativo e teorias de ensino da leitura, encorajando a prática reflexiva do professor em formação; e provocaram os licenciandos a sustentarem posições sobre os textos pautadas em suas percepções sobre a construção linguístico-discursiva destes (e não apenas em 'opiniões' sobre os temas contemplados nas obras).

As propostas de abordagem do texto literário, nessa turma, possibilitaram, assim, o trabalho com uma estéticaética discursiva, em que a forma de dizer não se desarticulou do lugar responsivo-responsável que se assume ao mobilizar a palavra. Trata-se, pois, da possibilidade de evocar memórias, de explorar a polissemia e os efeitos de sentidos possíveis a partir da materialidade linguística-discursiva dos textos (sempre em relação com a historicidade dos dizeres).

Voltando à noção de experiência defendida por Larrosa (2011), cremos que a forma como cada professor em formação pode (res)significar o texto e atribuir sentidos é singular - apesar de construída socialmente e não no âmbito da individualidade. Assim, entendemos que propostas como essa podem incidir na constituição desses sujeitos como leitores e (futuros) professores. Não há, contudo, garantias de 'sucesso', de objetivos alcançados, de metas educacionais atingidas. A experiência se assenta no princípio da incerteza,

Porque a abertura que a experiência dá é a abertura do possível, mas também do impossível, do surpreendente, do que não pode ser. Por isso a experiência sempre supõe uma aposta pelo que não se sabe, pelo que não se pode, pelo que não se quer. A experiência é um talvez. Ou, o que é o mesmo, a experiência é livre, é o lugar da liberdade. (LARROSA, 2011, p. 19).

É nessa possibilidade de incerteza que reside, também, a marca do desafio. Garantir o entrecruzamento de duas áreas afins e tão úteis a si como língua e literatura é tarefa imprescindível aos currículos atuais, bem como provocar a união de ambas objetivando o desenredar das divergências teóricas. É urgente que se pense nessa confluência e trabalhá-la nas disciplinas dos currículos atuais, visando a um aproveitamento mais frutífero e producente na formação do futuro professor.

\section{(DES)ENCONTROS FINAIS}

Nosso intuito neste trabalho foi o de lançar reflexões sobre a necessidade de se repensar a articulação entre o ensino de literatura e língua inglesa na formação do professor, a partir de uma perspectiva não dicotômica entre língual 
literatura e aprender língua/aprender a ser professor de língua. Para isso, discutimos uma proposta pedagógica implementada em um curso com foco na aprendizagem de leitura em língua inglesa, a qual procurou aventar experiências com o texto literário que possibilitassem, ao futuro professor, modos outros de enunciar e perceber a língua alvo. Como dissemos anteriormente, o leitor não mais é visto do ponto de vista do intérprete da "intenção do autor", e sim como sujeito que, a partir de seu contexto sócio-histórico, ideológico e cultural, se implica em sua leitura, de forma responsiva e responsável, marcando seu lugar ético-estético no mundo.

Há de se acrescentar que a preocupação atual parece ganhar outra tendência: a de como devemos nos comportar perante a presença cada vez mais evidente do que se pode chamar do leitor do futuro. Evidentemente há implicações ao lidar com esse sujeito, que começa a se formar leitor em princípios do século XXI, implicações essas que parecem causar conflito entre ele e o leitor do passado. Em síntese, o leitor do passado era apegado ao livro, ao papel, cujas leituras eram compartimentadas. O leitor do presente/futuro está em outras dimensões: ele está exposto a uma grande gama de textos, em diferentes suportes e formatos, que, como dito, transcendem a palavra. Tomamos a afirmação de Zilberman ao atualizar esse modo de ler, cujo impacto se agiganta cada vez mais:

Com efeito, a imposição das Tecnologias da Informação e Comunicação [TICs] fez com que outras possibilidades de criação e difusão artística aparecessem e se firmassem, ameaçando a hegemonia do livro impresso e de seu representante mais ilustre, o texto artístico, aquele que as teorias da leitura prezam, examinam e explicam. Primeiramente, porque novas possibilidades de registro se impuseram, como os arquivos digitais, que circulam por meio de aparelhos específicos e mais portáteis que o livro. Depois, porque as alternativas de produção passaram a incluir elementos que não se limitam à "letra", ainda que não possam ignorá-la, incluindo som, imagem, performance e interação. Os dois últimos fatores mencionados - interação e performance - são os mais instigantes, porque incidem não apenas na participação do sujeito criador, mas também daquele que, na acepção das teorias da leitura ou da comunicação, seria o recebedor ou o destinatário, transformado doravante em criador, em decorrência do novo tipo de diálogo. ZILBERMAN (2017, p. 16)

O leitor do futuro configura-se, portanto, como um diferenciador de suportes e intérprete das mais variadas manifestações estéticas, nos mais diferentes formatos, alguns dos quais ainda não nos foram dados a conhecer, mesmo porque o ato de ler, no futuro, terá significado cada vez mais diluído, obrigatoriamente relacionado com o comportamento humano quanto às visões diferenciadas de mundo, de diversidade, de sociedade e de inserção global. Ler, no futuro, passará por modelos renovados de ética, de política e de espaços reais/virtuais.

Assim, neste espaço da contemporaneidade e com vistas ao que virá, é que pensamos, ao longo deste trabalho, noções (des)encontradas de texto, literatura e leitor, sendo este último representado, nos cursos de licenciatura, pelo professor em formação. Esse sujeito é, portanto, o centro de nossa preocupação por estar ele ao mesmo tempo em formação e ter a sua experiência (de vida e de leitura) validada. Essa discussão norteará, de maneira sólida, a integração ensino-aprendizagem de literatura nas aulas de idiomas, e de idiomas nas aulas de literatura; bem como possibilidades de reconfiguração dos currículos das licenciaturas em Letras.

\section{REFERÊNCIAS}

BAKHTIN, M. (1979). Estética da criação verbal. 3. ed. Trad. Maria Ermantina Galvão. São Paulo: Martins Fontes, 2000.

BRASIL. Ministério da Educação. (2017). Base Nacional Comum Curricular. Versão final. Brasilia: Ministério da Educação. Disponível em: http://basenacionalcomum.mec.gov.br/ Acesso em: 30 abril 2020.

BRITO, C. C. P.; GUILHERME, M. F. F. (2017). A constituição do professor de inglês pré-serviço em um curso de Letras EaD: representações sobre formação, ensino-aprendizagem e tecnologia. Linguagem em (Dis)curso, v. 17, n. 1, pp. 117-136.

BRITO, C. C. P.; GUILHERME, M. F. F. (2014). Memorial de aprendizagem e a formação do professor: vozes constitutivas da relação aprender/ensinar línguas estrangeiras. Revista Brasileira de Linguística Aplicada, v. 14, n. 3, pp. 511-532.

BRITO, C. C. P.; HASHIGUTI, S. T. (2019). Produção e avaliação de material didático em um curso de Letras Inglês a distância: sobre a tomada da palavra em LE e um lugar discursivo crítico. Caminhos em Linguística Aplicada, v. 21, n.2, pp. 108-132.

BRITO, C. C. P.; RIBAS, F. C. (2019). "Como se forma um professor de língua inglesa?”: reflexões a partir da reforma curricular de um curso de Letras. Revista Letras Raras, v.8, n. 3, pp. 9-35. 
BRUN, M. (2004). (Re)construção identitária no contexto da aprendizagem de línguas estrangeiras. In: MOTA, K; SCHEYERL, D. (Orgs.). Recortes interculturais na sala de aula de línguas estrangeiras. Salvador: EDUFBA, pp. 73-104.

CLÜVER, C. (2014). Inter-textus/inter-artes/inter-media. Aletria: Revista de Estudos de Literatura (UFMG). v. I, n. 14, pp. $11-41$

COMPAGNON, A. (1999). O demônio da teoria: literatura e senso comum. Tradução de Cleonice Paes Barreto Mourão. Belo Horizonte: Ed. UFMG.

ECO, U. (2005). Obra Aberta: forma e indeterminação nas poéticas contemporâneas. São Paulo: Perspectiva.

EAGLETON, T. (1985). Teoria da literatura: uma introdução. Tradução Waltensir Dutra. São Paulo: Martins Fontes.

FRANÇA, T. M. (2019). O ensino de literatura sob a ótica da interface teórica entre a linguística aplicada transgressiva, a Análise do Discurso e os estudos do Círculo de Bakhtin. In: STAFUZZA, G. B.; FONSECA, P. A. (Orgs.). Estudos discursivos em múltiplas perspectivas: discurso, sujeito, sociedade. Campinas, SP: Mercado de Letras, pp. 91-114.

GARCÍA-MARQUEZ, G. (2016). 100 anos de solidão. Rio de Janeiro: Record.

GUILHERME, M. F. F. (2017). Línguas estrangeiras: ensino-aprendizagem e formação política de professores. In: FIGUEIRABORGES, G.; SILVA, M. A. (Orgs.) Ensino de linguas em diferentes contextos. Campinas, SP: Pontes Editores, pp. 15- 28.

HALL, G. (2015). Language, Literature and Education. In: Literature in Language Education. 2nd edition. New York: Palgrave Macmillan, pp. 9-98.

ISER, W. (1996). O Ato da Leitura: uma teoria do efeito estético. Tradução de Johannes Kreschmer. São Paulo: Ed. 34.

KUMARAVADIVELU, B. (2003). Integrating language skills. In: Beyond methods: macrostrategies for language teaching. New Haven and London: Yale University Press, pp. 225-238.

LARROSA, J. (2011). Experiência e alteridade em educação. Revista Reflexão e Ação, Santa Cruz do Sul, v. 19, n. 2, pp. 04-27. Disponível em <https://online.unisc.br/seer/index.php/reflex/article/view/2444>. Acesso em: 24 abr. 2020.

LAZAR, G. (1993). Literature and Language Teaching: A guide for teachers and trainers. Cambridge: CUP.

LOPES, L. C. V.; COSTA, M. E. da.; SAMPAIO, M. L. P. (2011). Letramento literário e formação do professor: o ensino de literatura no meio universitário. Entreletras, n. 3, pp. 63-80.

MOTA, F. (2010). Literatura e(m) ensino de língua estrangeira. Fólio - Revista de Letras, v. 2, n.1, pp. 101-111. Disponível em $<$ http://periodicos2.uesb.br/index.php/folio/article/view/3628>. Acesso em: 24 abr. 2020

NAJI, J.; SUBRAMANIAM, G.; WHITE, G. (2019). New Approaches to Literature for Language Learning. Palgrave, Macmillan.

MOITA LOPES, L. P. (Org.). (2006). Linguística Aplicada e vida contemporânea: problematização dos construtos que têm orientado a pesquisa. In: Por uma linguística aplicada INdisciplinar. São Paulo: Parábola Editorial, pp. 85-107.

SZUNDY, P. T. C. (2014). Educação como ato responsável: a formação de professores de linguagens à luz da filosofia da linguagem do círculo de Bakhtin. Trabalbos em Linguística Aplicada, v. 53, n.1, pp. 13-32.

TÜRKER, F. (1991). Using "Literature" in language teaching. Disponível em: <http://static.dergipark.org.tr/article-download/ imported/5000049295/5000046616.pdf? >. Acesso em: 28 abr. 2020

UNIVERSIDADE FEDERAL DE UBERLÂNDIA. (2017). Instituto de Letras e Linguística. Projeto pedagógico do Curso de Graduação em Letras: inglês e literaturas de língua inglesa. [Uberlândia: UFU].

UNIVERSIDADE FEDERAL DE UBERLÂNDIA. (2007). Instituto de Letras e Linguística. Projeto político pedagógico do Curso de Letras. [Uberlândia: UFU]. 
UR, P. (1996). A Course in Language Teaching: theory and practice. Cambridge: CUP.

ZILBERMAN, R. (2017). A dialética da leitura entre a democratização e o cânone. In: PEREIRA, D. C. Nas linbas de Ariadne: literatura e ensino em debate. Campinas: Pontes.

Recebido: 30/4/2020

Aceito: 26/8/2021

Publicado: 14/9/2021 